\title{
Assessment of Vegetative Phenology with Respect to Leaf Elongation Patterns on Avicennia marina and Rhizophora mucronata in Hajambro Creek, Indus Delta, Pakistan
}

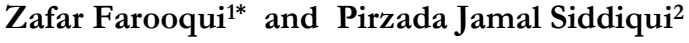 \\ ${ }^{1}$ Center of Excellence in Marine Biology, University of Karachi \\ ${ }^{2}$ Government Degree Boys College, KMC-Store, Nishtar road, Karachi
}

\begin{abstract}
Leaves emergence and the rate of elongation have been studied in Hajambro creek in Indus deltaic region, Pakistan. Leaves emergence was observed higher during the summer months (mostly premonsoon period), that was March April, May and June. Leaves of $A$. marina that were observed from March to July, till the leaves reached their maximum length (about $77 \mathrm{~mm}$ ), showed a gradual increase in their length, reaching maximum in April. Leaves of Avicennia marina reached their maximum length (about $77 \mathrm{~mm}$ ) in about 113 days. The leaves showed gradual increase in their length, reaching maximum on April $\left(0.97 \mathrm{~mm} \mathrm{~d}^{-1}\right)$. The per-day increase in length was $0.54 \mathrm{~mm} \mathrm{~d}^{-1}$. As reaching their maximum length $(77 \mathrm{~mm})$, the per-day increase in the length gradually slower down. The leaves of Rhizophora mucronata were seen from February to November. The leaves of Rhizophora mucronata showed elongation rate of $0.24 \mathrm{~mm} \mathrm{~d}^{-1}$ from the day of the first observation till the leaves reached their maximum length $(120 \mathrm{~mm})$. The maximum time required by the leaves to reach their maximum length $(120 \mathrm{~mm})$ was 236 days. The rates of elongation of leaves are also fast in summer. The rate of elongation of the leaves was found to be highly correlated with the temperature $(p<0.005)$. It was also found that the leaves grew faster on low salinity (in July and August). During these months, the salinity in the creek waters was the lowest (up to 10-12\%) when the downstream flow was the highest. The abscission time was found during September, October, November and December. Therefore, the leaves fall was found highly correlated with the litter fall research as most of the leaves fall was also higher during this drier season. Our results strongly endorsed the previous hypothesis that a fresh water is needed for the fast growth rates of mangroves. The stunted growth of Avicennia marina in the Indus delta, Sindh is due to a negligible amount of fresh water available to the delta, through downstream flow, only in July. Therefore, better management of water resources is necessary for the conservation and management of the mangrove forest of Indus delta, Pakistan.
\end{abstract}

Keywords: Avicennia marina, Rhizophora mucronata, mangrove, Indus delta, phenology

\section{INTRODUCTION}

Mangroves are among the world's most productive ecosystems, enriching coastal waters, with noticeable seasonality in their litter production [1]. The information on phenology is useful

*Corresponding author:

Zafar Farooqui

Center of Excellence in Marine Biology, University of Karachi

E-mail: zafar_researchfellow@yahoo.com in predicting the interactions of plants and animals to the changing environment [2]. Phenological events can be assessed directly not only through observation but also through indirect evidence, e.g. from litter fall, if the possible time lag between formation and shedding of plant organs is known. Phenological research on vegetative developments of mangroves, such as leaf emergence and loss on leafy shoots, allow for estimates of leaf turnover and leaf longevity [2, 3, $4,5]$. 
The phonological studies of plants are essential in understanding of ecosystem functioning [6]. The importance of growth and phonological research in better understanding the ecological functioning have led to the afforestation of mangroves, especially in Asian countries $[7,8,9]$. In Australia, the phenology of at least 35 mangrove species has been documented $[5,10]$. This study is also helpful in understanding the population dynamics of mangroves [11-24]. However, many countries of the world including Pakistan have lost their original mangroves covered area $[15,25]$ mainly due to the deforestation.

In order to conserve the natural forest, in $\mathrm{Pa}$ kistan, in Keti-Bunder area of Hajambro creek Indus delta, forest department has introduced R.mucronata. which is not a common species in the Indus deltaic area. They are apparently growing in a regular manner. Here, the examination of the leaf elongation pattern of A.marina and R.mucronata has been provided. Despite the relevance of the phenological events in the mangrove system, due to their essential relationship with litter production and reproductive success of the species, no such study has been conducted with the phonological aspects of mangrove forest of Indus delta, Pakistan. Therefore, it was desirable to conduct these studies in their natural environment in the Keti-Bunder area of Indus delta region, Pakistan.

\section{MATERIALS AND METHODS}

\section{Study area}

This study was conducted on mangrove plants growing in mangrove forests at Hajambro Creek (Indus delta) located at $2411.126^{\circ} \mathrm{N}, 06726.97^{\circ}$ E. This area has naturally growing A. marina plants along with their saplings and planted $R$. mucronata.

\section{Climate}

The hottest months in the area is May and June with temperature reaching at $40^{\circ} \mathrm{C}$ while December and January are the coldest sessions $\left(9^{\circ} \mathrm{C}\right)$. The highest precipitations occurs in August, having $34.5 \mathrm{~mm}$ rainfall. The highest humidity (90\%) in August, mostly due to the rainy season while the minimum humidity $(24 \%)$ occurs in April and March. Pakistan is relatively weak and of short monsoon duration, falling mainly in July and August. The Indus flow 275 million cubic yards of water annually, twice than the Nile river [26].

\section{Monitoring of leaves and measurement of leaf length}

We tacked shoots (first order) in sunlit positions in the outer part of the canopy of each Avicennia marina and Rhizophora mucronata trees. To distinguish the growth produced over an interval, we labeled the leaves in the apical position on each of these shoots at each sampling period. We observed the length of all the leaves from the day of the first observation until the reaching of leaves to its maximum length. We also observed the arrival of any lateral shoot and appearance and length of all the leaves on lateral shoots, fortnightly as possible. However here, we are presenting the elongation rate of the leaves arising on the main shoot tagged. From these observations, we observed the increase in the length of the leaves at each time intervals (days) and calculated the per-day increment in the length of the leaves after dividing the days interval between the two observations.

\section{Statistical analysis}

Regression coefficient was evaluated for leaf elongation against the time. Minitab 14 versions were used for all the statistical analysis.

\section{RESULTS AND DISCUSSION}

\section{Elongation rate of Avicennia marina leaves}

Leaves of Avicennia marina reached their maximum length (about $77 \mathrm{~mm}$ ) in about 113 days (Fig $2)$. The leaves showed gradual increase in their-

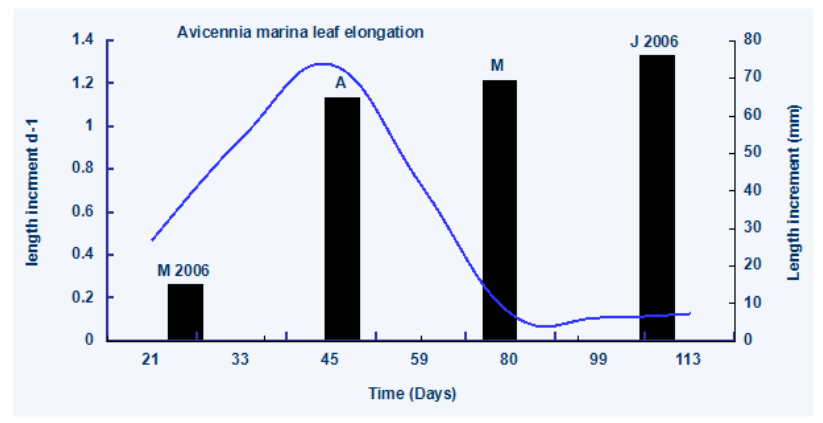

Figure 2 Leaf length increment (Bars) and leaf length increment per day (Line) in Avicenna marina leaves in Hajambro creek, Indus delta 


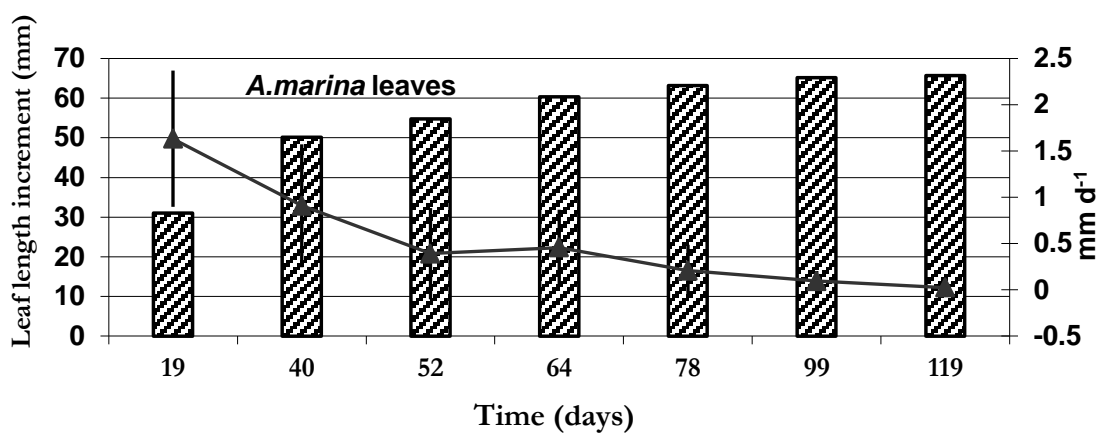

Figure 3 Mean $( \pm S D)$ elongation rates (bars) and per day increment (line) of ten leaves, till reaching to maximum length, of A. marina on different shoots, monitored in Hajambro creek in Indus deltaic region, Pakistan

length, reaching maximum in April $\left(0.97 \mathrm{mmd}^{-1}\right)$. The per-day increase in length was $0.54 \mathrm{mmd}^{-1}$. As reaching to their maximum length $(77 \mathrm{~mm})$, the per-day increase in the length gradually slower down (Fig 2). The rates of elongation of leaves are also fast in the sum-mer season (Fig.2 and Fig.3, Table I). These results are highly correlated with the temperature $(p<0.005)$. It was also found that the leaves grow faster on low salinity (in July and August).

Table 1. Regression coefficient equation for R.mucronata and A.marina leaf elongation with time elapsed.

\begin{tabular}{l|c|c}
\multicolumn{1}{c|}{ Mangroves leaf } & Regression equation & $\mathrm{R}^{2}$ \\
\hline R.mucronata & $\mathrm{y}=65.3+0.262 \mathrm{x}$ & 0.837 \\
A.marina & $\mathrm{y}=32.2+0.379 \mathrm{x}$ & 0.718
\end{tabular}

\section{Elongation rate of Rhizophora mucronata leaves}

The leaves of Rhirophora mucronata showed elongation rate of $0.24 \mathrm{mmd}^{-1}$ from the day of the first observation till the leaves reached their maximum length $(120 \mathrm{~mm})$. The maximum time required by the leaves to reach their maximum length $(120 \mathrm{~mm})$ was 236 days (Fig 4 and 5). The comparative elongation rate of north Avicennia marina and Rhizophora mucronata can be seen in Fig 6,7 , and 8 . During these months, the salinity in the creek waters was the lowest (up to $10-12 \%$ ). The abscission period was found during September, October, November and December 2006. Therefore, the leaves fall was found to be highly-

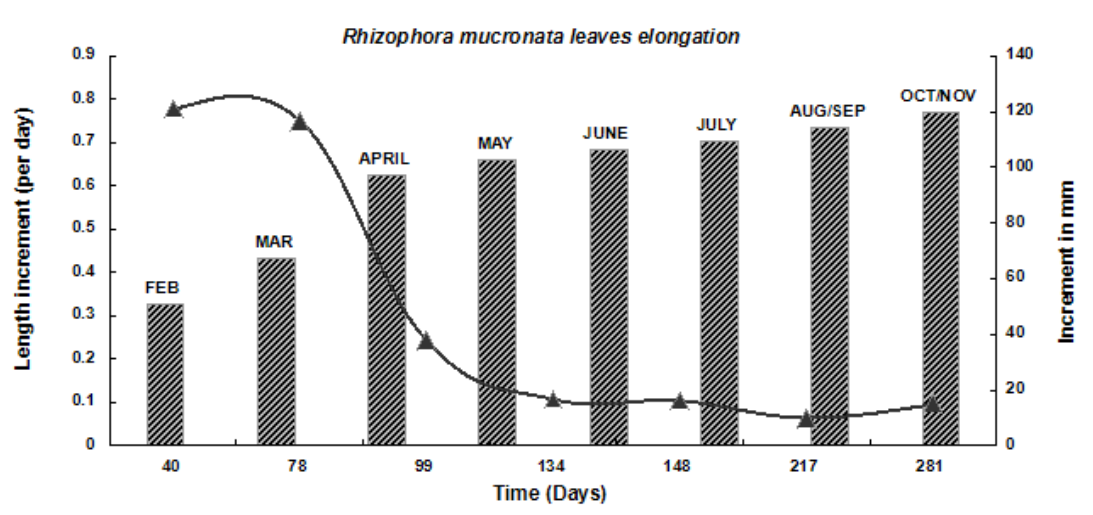

Figure 4. Leaf length increment (Bars) and leaf length increment per day (Line) in Rhizophora mucronat leaves in Hajambro creek, Indus delta

correlated with the litter fall studies, as most of the leaves fall was also higher during this drier season. Our results strongly endorsed the previous hypothesis that a fresh water is necessary for the fast growth rates of mangroves. The stunted growth of Avicennia marina in the Indus delta,
Sindh is due to a negligible amount of fresh water available to the delta, through downstream discharge, only in July. Therefore, better management of water resources is necessary for the conservation and management of the mangrove forest of Indus delta, Pakistan. 


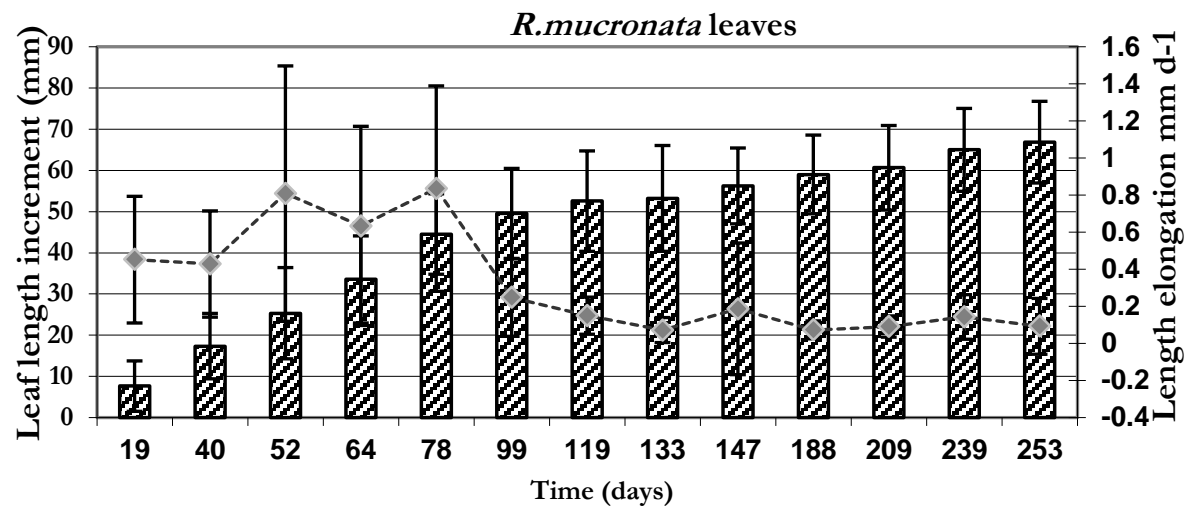

Figure 5. Mean $( \pm \mathrm{SD})$ elongation rates (bars) and per day increment (line) of ten leaves, till reaching to maximum length, of R. mucronata on different shoots, monitored in Hajambro creek in Indus deltaic region, Pakistan

\subsection{Discussion}

The results revealed that a leaf on the main stem of Avicennia marina and Rhizophora mucronata plants in Hajambro creek area of Indus delta were slower growth during the cold season and dry months, comparatively fast growth during the warm and rainy seasons. These results corres-
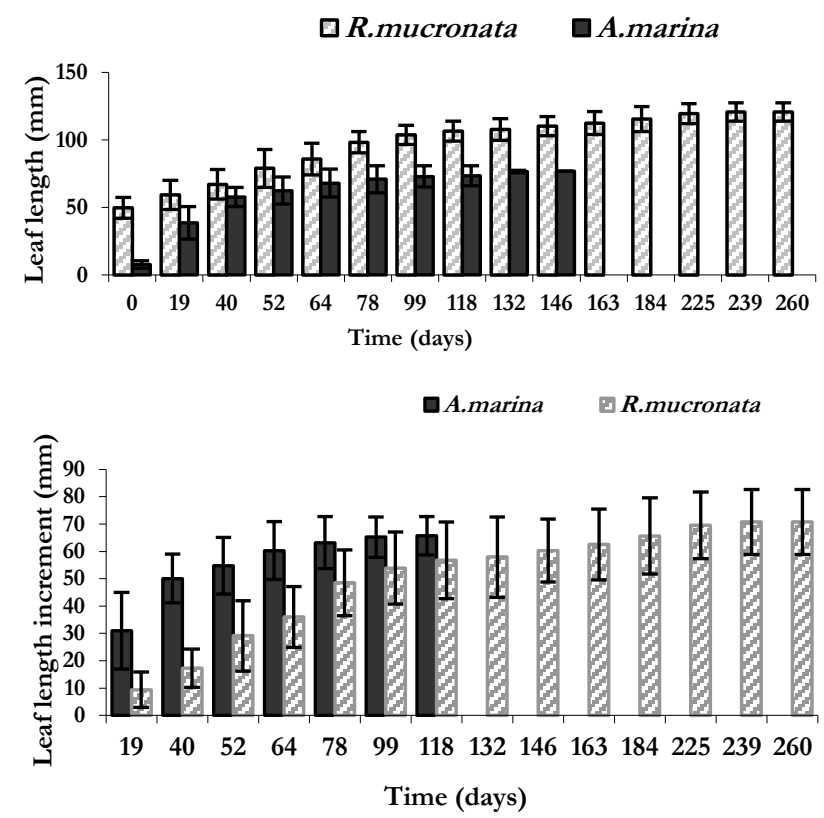

Figure 6. Leaf elongation of 10 pairs (total 20 leaves) leaves (mean $\pm \mathrm{SD}$ ) on 10 shoots of R.mucronata and $A$. marina along the time, in Hajambro creek

pond to the unimodal seasonality of the vegetative developments of mangrove plants reported by [27] especially Kandelia candel in Okinawa, Japan. Mangroves growth in the tropical climate although have uniform temperature [28], and the temporal changes in climate components, such as rainfall or irradiance, which can potentially affect plants growths [29, 30]. Moreover, unimodal and bimodal of the mangrove leaves production are associated with fluctuations of groundwater salinity [4]. High interstitial water salinity elevates stress in mangroves increased leaf to reduce wa-

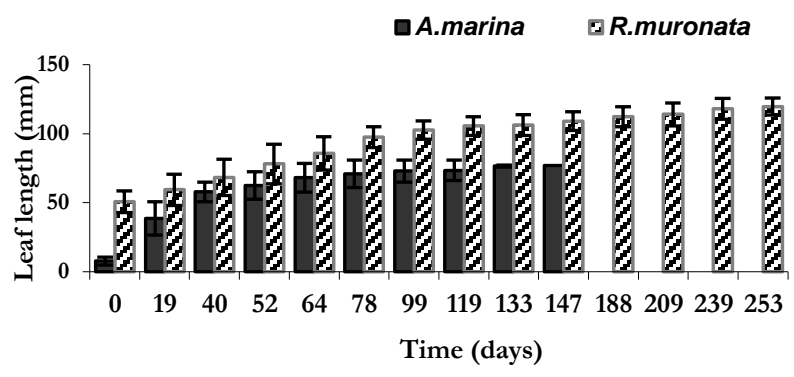

Figure 7. Leaf elongation (mean $\pm \mathrm{SD}$ ) of R.mucronata, observed from March 2006 until Nov 2006, and A.marina leaf from March 2006 until July 2006, in Hajambro creek, Indus delta, Pakistan

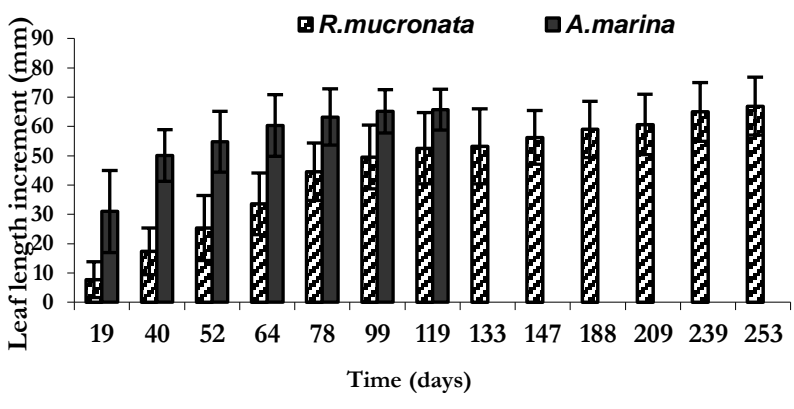

Figure 8. Leaf emergence and elongation (mean \pm SD) of 10 leaves on different shoots of R.mucronata and A.marina leaf in Hajambro creek, Indus delta, Pakistan 
ter loss from transpiration, especially during the dry season $[29,30]$. The lower leaf fall and emergence may also be related to the reproductive status of the trees at that time $[29,30,31]$. There was possibly a link between vegetative production and the reproductive cycle in that there was-
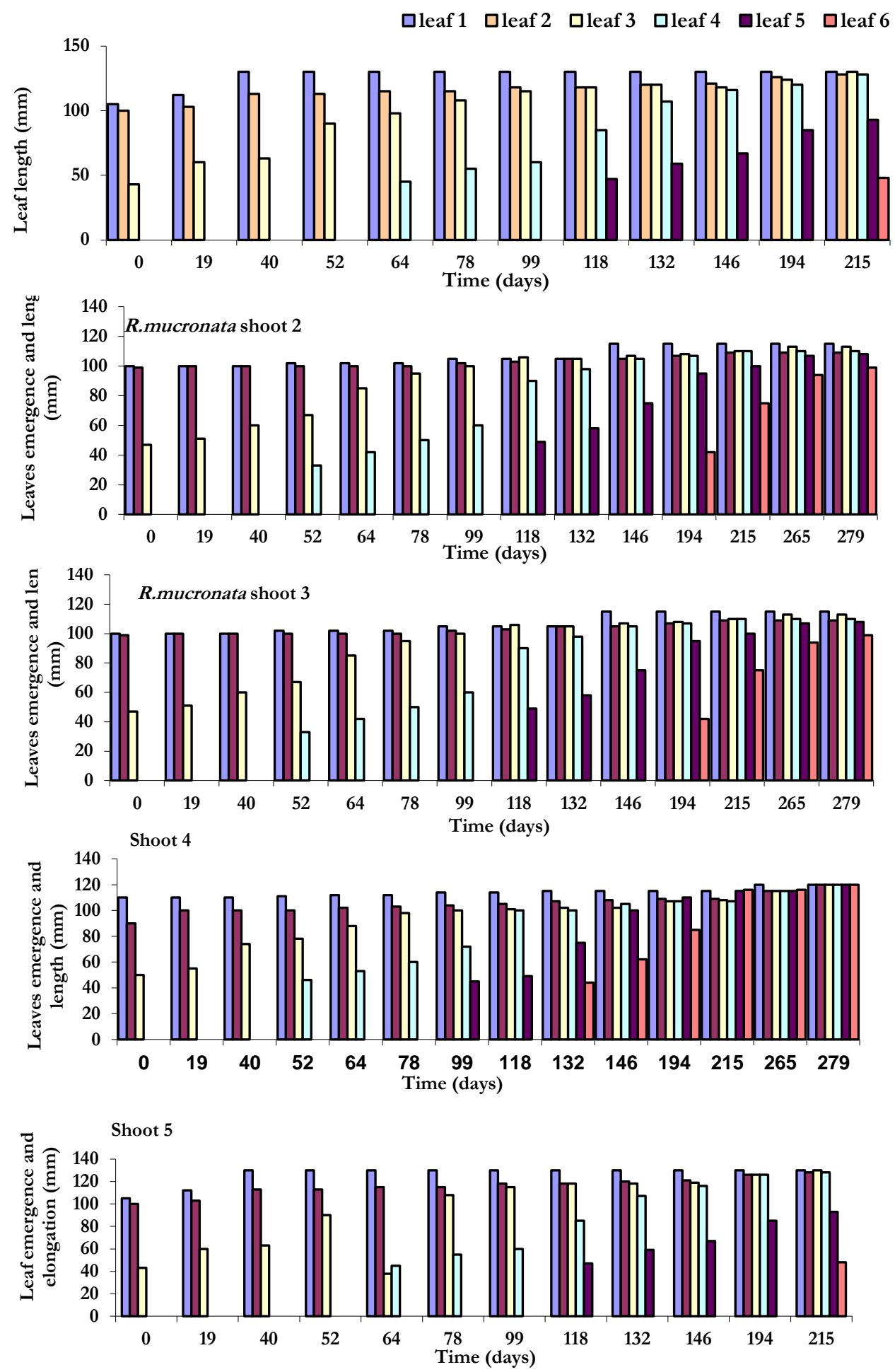

Figure 9. Leaves emergence and elongation of length of five shoot of R.mucronata, observed from February 2006 until November 2006 in Hajambro creek, Indus delta, Pakistan. 


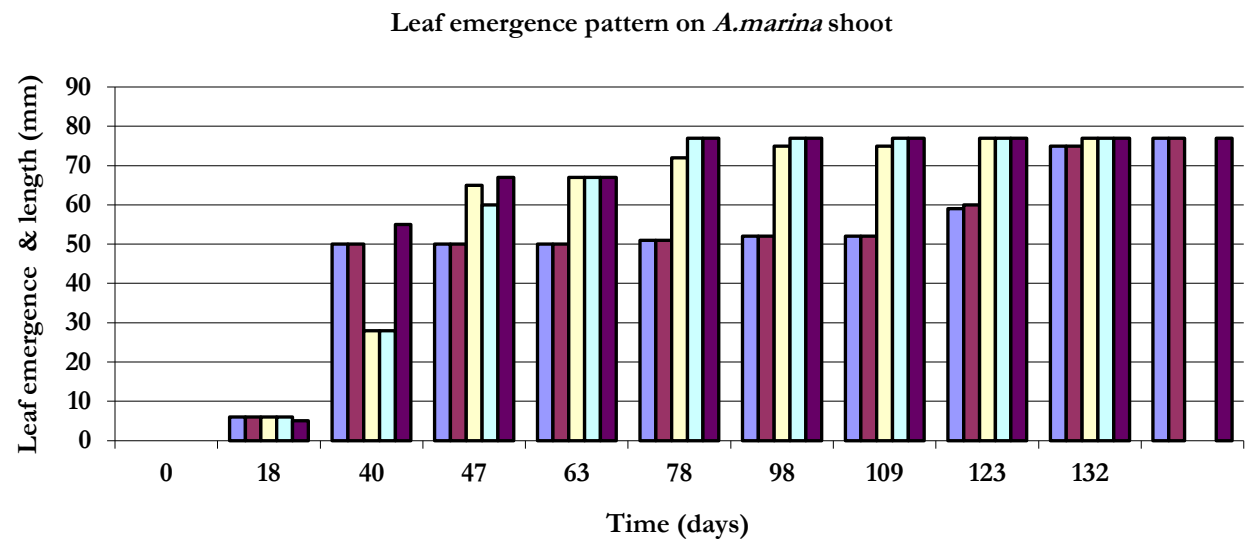

Figure 10. Leaf emergence and their mean $( \pm \mathrm{SD})$ length elongation on a shoot of $A$. marina in Hajambro creek, Indus delta, Pakistan

very little vegetative activity while the trees were flowering and fruiting, and leaf production and fall only resumed in June after completion of fruit fall. These results are corroborated by other studies [5, 3, 31].

Other mangroves growing in the subtropical area demonstrate strong seasonality in their vegetative development of various species of mangrove [29, 30, 32]. Mangroves growing in the tropical locations, however, usually show multimodal seasonal signals in their vegetative growth [11, 3, 4, 29, 33]. Mangroves grow continuously during the year, and the temporal variability of the environmental condition influences plant growth resulting in different patterns of seasonality $[34,11,3,4,30]$.

\section{CONCLUSION}

The stunted growth of Avicennia marina in the Indus delta is due to a negligible amount of fresh water available. The better management of water resources is necessary for the conservation and management of the mangrove forest of Indus delta, Pakistan.

\section{ACKNOWLEDGEMENT}

We greatly acknowledge the support of Higher Education Commission of Pakistan for providing the Indigenous Ph.D Scholarship for First Author (PIN NO IKB 0349090). The people of the Center of Excellence in Marine Biology, the University of Karachi are also acknowledged for their logistic support during the study. The Metrological Department is highly acknowledged for providing the metrological data of the area.

\section{REFERENCES}

1. Tomlinson, P. B. 1986. The botany of mangroves. Cambridge University Press, Cambridge, United Kingdom.

2. Bhat DM, Murali KS (2001) Phenology of Under Storey Species of Tropical Moist Forests of Western Ghats Region of Uttara Kannada District in South India. Current Science 91: 799805.

3. Wium-Andersen S, Christensen B (1978) Seasonal Growth of Mangrove Trees in Southern Thailand. II. Phenology of Bruguiera cylindrica, Ceriops tagal, Lumnitzera littorea and Avicennia marina. Aquatic Botany 5: 383-390.

4. Wium-Andersen S (1981) Seasonal Growth of Mangrove Trees in Southern Thailand. III. Phenology of Rhizophora mucronata Lamk. and Scyphiphora bydrophyllacea Gaertn. Aquatic Botany 10: 371-376.

5. Duke NC, Bunt JS, Williams WT (1984) Observations on the Floral and Vegetative Phonologies of North-eastern Australian Mangroves. Australian Journal of Botany 32: 87 99. Duke et al., 1984.

6. Janzen, D.H. 1967. Synchronization of sexual reproduction of trees within the dry season in Central America. Evolution 21: 620-673. 
7. Gomez EG (1988) Overview of Environmental Problems in the East Asian Seas Region. Ambio 17: 166-169.

8. Arrhenins J (1992) Protecting tropical and Subtropical Coastal Water: A Resource for Future Generations. Ambio 21: 388-490.

9. Aksornkoae S (1993) Ecology and Management of Mangroves (193 pp.). Bangkok: International Union for the Conservation of Nature.

10. Duke NC (2006) Australia's Mangroves. The Authoritative Guide to Australia's Mangrove Plants. University of Queensland, Brisbane. 200 pp.

11. Christensen B, Wium-Andersen S (1977) Seasonal Growth of Mangrove Trees in Southern Thailand. I. The Phenology of Rhizophora apiculata Bl. Aquatic Botany 3: 281-286.

12. Onuf CP, Teal JM, Valiela I (1977) Interactions of Nutrients, Plant Growth and Herbivory in a Mangrove Ecosystem. Ecology 58: 514-526.

13. Christensen B (1978) Biomass and Primary Production of Rhizophora apiculata Bl. in a Mangrove in Southern Thailand. Aquatic Botany 4: 43-52.

14. Lugo, AE \& Patterson-Zucca, C. 1986. Production, standing crops and decomosition of litter in basin mangrove forests in southwest Florida .Ecology 67:670-683

15. Saenger P.\&S.C.Snedaker.1993.Pantropical trends in mangrove above-ground biomass and annual litterfall.Oecologia 96:293-299.

16. Clarke PJ (1994) Baseline Studies of Temperate Mangrove Growth and Reproduction; Demographic and Litterfall Measures of Leafing and Flowering. Australian Journal of Botany 42: 37-48.

17. Bunt JS (1995) Continental Scale Patterns in Mangrove Litter Fall. Hydrobiologia 295: 135140

18. Feller IC (1995) Effects of Nutrient Enrichment on Growth and Herbivory of Dwarf Red Mangrove (Rhizophora mangle). Ecological Monographs 65: 477-505.

19. O'Grady, A.P., McGuinness, K.A. and Eamus, D. 1996. The abundance and growth of Avicennia marina and Rhozophora stylosa in the low shore zone of Darwin Harbour, Northern Territory. Australian Journal of Ecology 21: 272-279.

20. Clough BF, Ong JE, Gong WK (1997) Estimating Leaf Area Index and Photosynthetic Production in Canopies of the Mangrove Rhizophora apiculata. Marine Ecology Progress Series 159: 285-292.

21. Duarte CM, Geertz-Hansen O, Thampanya U, Terrados J, Fortes MD, Kamp-Nielsen L, Borum J, Boromthanarat S (1998) Relationship between Sediment Conditions and Mangrove Rhizophora apiculata Seedling Growth and Nutrient Status. Marine Ecology Progress Series 175: 277-283.

22. Ball MC (2002) Interactive Effects of Salinity and Irradiance on Growth: Implications for Mangrove Forest Structure Along Salinity Gradients. Trees 16: 126-139.

23. Clough B, Tan DT, Phuong DX, Buu DC (2000) Canopy Leaf Area Index and Litter Fall in Stands of the Mangrove Rhizophora apiculata of Different Age in the Mekong Delta, Vietnam. Aquatic Botany 66: 311-320.

24. Coulter SC, Duarte CM, Tuan MS, Tri NH, Ha HT, Giang LH, Hong PN (2001) Retrospective Estimates of Net Leaf Production in Kandelia Candel Mangrove Forests. Marine Ecology Progress Series 221: 117-124.

25. Saenger P.\&S.C.Snedaker.1993.Pantropical trends in mangrove above-ground biomass and annual litterfall.Oecologia 96:293-299.

26. Roberts TJ (1995) A pictorial view of the Indus River and mans impact on its role and resources. In The Indus River, Biodiversity, Resources and Humankind, Eds. Meadows A and Madows P. Oxford University Press. Pakistan. 91-99.

27. Gwada P, Makoto T, Uezu Y (2000) Leaf Phenological Traits in the Mangrove Kandelia candel (L.) Druce. Aquatic Botany 68: 1-14.

28. Strahler, A.N. 1988. Geografía Física. Omega, Barcelona

29. Duke NC (1990) Phenological Trends with Latitude in the Mangrove Tree Avicennia marina. Journal of Ecology 78: 113-133.

30. Clarke PJ (1994) Baseline Studies of Temperate Mangrove Growth and Reproduction; Demographic and Litterfall Measures of Leafing and Flowering. Australian Journal of Botany 42: 37-48.

31. Coupland Grey T, Eric IP, Keith AM (2005) Vegetative and Reproductive Phenologies of Four Mangrove Species from Northern Australia. Australian Journal of Botany 53(2): 109-117.

32. Osunkoya OO, Creese RG (1997) Population Structure, Spatial Pattern and Seedling Establishment of the Grey Mangrove, Avicennia marina var. Australasica, in New Zealand. Australian Journal of Botany 45: 707-725.

33. Ellison AM, Farnsworth EJ (1996) Spatial and Temporal Variability in Growth of Rhizophora Mangle Saplings on Coral Cays: Links with Variation in Insolation, Herbivory, and Local Sedimentation Rate. Journal of Ecology 84: 717 731.

34. Gill AM, Tomlinson BP (1971) Studies on the Growth the Red Mangrove (Rhizophora manggle L.) 3. Phenology of the shoot. Biotropica 3: 109 124. 